\title{
Frailty assessment in elective gastrointestinal oncogeriatric surgery: Predictors of one-year mortality and functional status
}

\author{
Chiara Giannotti ${ }^{\mathrm{a}, \mathrm{d}, 1}$, Silvia Sambuceti ${ }^{\mathrm{a}, \mathrm{d}, 1}$, Alessio Signori ${ }^{\mathrm{b}}$, Alberto Ballestrero ${ }^{\mathrm{a}, \mathrm{d}}$, Roberto Murialdo ${ }^{\mathrm{d}}$,

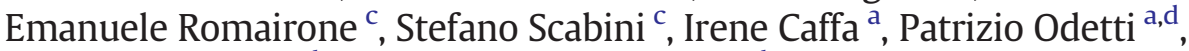 \\ Alessio Nencioni ${ }^{\mathrm{a}, \mathrm{d}, * *}$, Fiammetta Monacelli ${ }^{\mathrm{a}, \mathrm{d}, *}$ \\ a Geriatrics Clinic, Department of Internal Medicine and Medical Specialties (DIMI), University of Genoa, 16132 Genoa, Italy \\ ${ }^{\mathrm{b}}$ Department of Health Science (DISSAL), University of Genoa, 16132 Genoa, Italy \\ c Oncological Surgery and Implantable Systems, Hospital Policlinic San Martino, Genoa, Italy \\ d IRCCS Ospedale Policlinico San Martino, 16132 Genoa, Italy
}

\section{A R T I C L E I N F O}

\section{Article history:}

Received 31 August 2018

Received in revised form 3 April 2019

Accepted 21 April 2019

Available online $\mathrm{xxxx}$

\section{Keywords:}

Older adults

Cancer

Surgery

Frailty assessment

Long-term mortality and functional decline

\begin{abstract}
A B S T R A C T
Objectives: Perioperative frailty assessment is still a challenge, especially in oncogeriatrics. We aimed at assessing the diagnostic accuracy of the 40 items Frailty Index (FI) as compared to the comprehensive geriatric assessment (CGA) for the prediction of one-year mortality and functional status after colorectal surgery in old-age subjects. Material and methods: Ninety-nine consecutive patients aged 65 years or older who were candidate for elective gastrointestinal cancer surgery, with G8 score $\leq 14$ were enrolled and subjected to CGA and to frailty stratification according to the 40-items FI. Long-term outcomes including one-year mortality and functional decline were collected.

Results: Mean patient age was $80.3 \pm 5.6$ years. Colorectal cancer was the most common diagnosis. The most prevalent clinical phenotype was pre-frail. CGA and FI showed similar predictive accuracy in identifying oneyear mortality after surgery and patient functional status. Our multivariate analysis indicated the pre-morbid functional status (IADL) and cancer stage as the most significant predictors of one-year mortality.

Conclusions: This is the first study to investigate the prognostic accuracy of the 40-items FI as compared to CGA in a vulnerable octogenarian cancer population. Its results are consistent with patient functional status being a mediator of frailty and with both serving as intertwined markers of clinical vulnerability. In addition, according to our results, cancer and specific environmental stressors, such as surgery, are likely to affect the frailty trajectory.
\end{abstract} (c) 2019 Elsevier Ltd. All rights reserved.
Abbreviations: CGA, Comprehensive Geriatric Assessment; SIOG, International Society of Geriatric Oncology; NCCN, National Comprehensive Cancer Network; EORTC, European Organization for Research and Treatment of Cancer; FI, Frailty Index; SF36, Short Form 36; MNA, Mini Nutritional Assessment; GA, geriatric assessment; MMSE, Mini Mental State Examination; CDT, Clock Drawing Test Shulman; GDS, Geriatric Depression Scale; I-ADL, Instrumental Activities of Daily Living; TUG, Timed "Up \& Go" test; CIRS, Cumulative Illness Rating Scale; SI, Illness Severity Index; CI, Co-morbidity Index; NRS, Numeric Rating Scale; SVI, social vulnerability index; SD, standard deviation; IQR, median and interquartile range; AUC, Area under the curves;; ROC, Receiver operating characteristic.

* Correspondence to: Fiammetta Monacelli, Assistant Researcher in Geriatrics, DIMi, Department of Internal Medicine and Medical Specialties, University of Genoa, Genoa, Italy.

** Correspondence to: Alessio Nencioni, Department of Internal Medicine and Medical Specialties, University of Genoa, Genoa, Italy.

E-mail addresses: alessio.nencioni@unige.it (A. Nencioni), fiammetta.monacelli@unige.it (F. Monacelli).

${ }^{1}$ Equally contributing first authors.

\section{Introduction}

Due to the aging of populations worldwide and to the rising incidence of cancer with age, the surgical management of older patients is becoming more and more a key issue [1].

Surgery is the most efficient treatment for several solid cancers and recent technical advances with improved perioperative care have led to an increased number of older adults eligible for oncogeriatric surgery $[2,3]$

Postoperative mortality is a key outcome measure after cancer surgery, especially for high-risk older populations. However, while most studies considered 30-day postoperative mortality as a clinical end point, there is increasing evidence for a high mortality beyond 30 days [4].

Indeed, the exceeding postoperative mortality, up to 1 year after surgery, has been indicated as the most discriminant factor for long-term survival in elderly patients with colorectal cancer $[5,6]$. 
The heterogeneity of biological aging mandates the accurate identification of a patient's vulnerability in order deliver individualized treatments $[7,8]$. Chronological age alone can no longer be considered the sole exclusion criterion for cancer surgery [2]. The presence of comorbidity [9], functional decline, and older age [10] were reported to play an important role in postoperative outcomes in elderly patients with gastrointestinal malignancies.

The inability of traditional risk assessment tools to estimate older patients' physiologic reserve after surgery has resulted in a growing interest in preoperative geriatric assessment [11].

The International Society for Geriatric Oncology (SIOG) recommended a two-step diagnostic assessment in patients aged 65 or older, consisting of an initial screening to identify vulnerable patients (e.g. G8 or VES-13) and of a comprehensive geriatric assessment (CGA) in those patients who score positive at the initial screen [12].

In line with these recommendations, the American College of Surgeons and the American Geriatrics Society also recommended a preoperative frailty assessment for all older adults who are candidates for surgical procedures [13].

Growing evidence indicates a role for CGA in the perioperative prediction of adverse clinical outcomes, including morbidity [14-17], short-term mortality $[15,18]$ and mortality $[19]$ in elderly cancer patients undergoing surgical interventions.

So far [20-24], progression-free survival and overall survival still represent the most commonly reported clinical outcomes for older adults, while long-term functional status, physical performance and frailty trajectories should represent the mainstay instead [ 17,25,26].

Given this scenario, we sought to compare the accuracy of CGA vs. Rockwood's 40-items Frailty Index (FI) in predicting one-year mortality and functional status after surgery in elderly patients with gastrointestinal cancer. In addition, we aimed at defining the clinical variables that best predict one-year mortality after surgery.

\section{Materials and Methods}

\subsection{Study Design and Patients' Selection}

This is a prospective study performed at the oncological gastrointestinal surgery ward of the IRCCS Ospedale Policlinico San Martino, Genoa, Italy.

From January 2015 to December 2017, 123 older cancer patients, candidate for elective gastrointestinal surgery were consecutively enrolled.

The study was approved by the Local Ethical Committee and met the guidelines of the local Governmental Agency. The study has been carried out in accordance with the Code of Ethics of the World Medical Association (Declaration of Helsinki).

Patients were included if they were $>65$ years old, had a diagnosis of solid gastrointestinal tumour, were candidate for surgery, had a G8 questionnaire [27] score $\leq 14$, had adequate understanding of the Italian language and the ability to sign an informed consent.

Patients were excluded if they were younger than 65 years, had any clinical instability, received emergency surgery, had advanced dementia or pre-existing major neurological and/or psychiatric disorders.

\subsection{Geriatric Assessment}

The pre-operative clinical assessment was performed within 0 -14 days before elective surgery at the hospital geriatric outpatient office by an expert trained geriatrician.

Patients with a score $\leq 14$ on the G8 screening tool [27] received the comprehensive geriatric assessment (CGA) (Appendix A) [28-38] and the frailty assessment [39], based on FI [40] (FI). Patients were defined as frail if they had a score of 3 or more altered domains to the CGA [41]. Namely, Tinetti scale [31] was meant to assess postural instability, Morse scale was meant to assess the risk of falls [31], whilst Gijon scale
[38] to assess social vulnerability. On the basis of the FI assessment, a score of $\leq 0.08$ defined patients as fit; a score of $\geq 0.25$ as frail and a score between 0.08 and 0.25 defined patients as pre-frail [39].

Timed up \& go test [42] (TUG) was used to assess the physical performance.

\subsection{Data Collection}

Demographic data (age, gender), tumour characteristics (site, local or metastatic) and the prevalence and types of geriatric recommended clinical interventions were collected.

Post-operative complications were recorded on the basis of ClavienDindo classification scale [43].

After twelve months from surgery, Barthel Index telephone interview (BII) was administered to assess long-term functional status [44]. Functional decline was defined as mild (BII > 80), moderate (BI: 21 to $79)$ and severe $(\mathrm{BI} \leq 20)$. One-year mortality was also recorded.

\subsection{Statistical Analysis}

The descriptive analysis for quantitative variables was expressed as mean and standard deviation (SD).

Receiver operating characteristic (ROC) curves were used to compare CGA and FI and to compare their ability in predicting short-term mortality and post-operative complications. Area under the curves (AUC) with $95 \% \mathrm{CI}$ were reported.

Receiver operating characteristic (ROC) curves were used to compare CGA and FI and to compare their ability in predicting 1-year mortality and 1-year functional status. Area under the curves (AUC) with 95\% CI were reported.

The association between categorical data was performed with the two-tailed $\chi 2$ or the Fisher exact test, when appropriate.

The non -parametric Mann-Whitney $U$ test was used to compare patients on quantitative measures.

Spearman correlation coefficient was used to assess the correlation between two clinical variables, when appropriate.

All measures that were found to be significant at univariate analysis were included into the multivariable model according to a stepwise approach after adjustment for age and gender. Specifically, a p value of 0.10 was used as threshold for inclusion into the multivariate model and $\mathrm{p}<0.05$ was considered as statistically significant.

Graph Pad v.5.0b and Stata (v.14; StataCorp) were used for the computation.

\section{Results}

\subsection{Patients' Clinical Characteristics}

Between January 2015 and December 2017, one-hundred and twenty-three gastrointestinal cancer patients, who were candidate for elective surgery, were consecutively enrolled. All patients underwent a two steps oncogeriatrics assessment (i.e. G8 screening test and CGA assessment). At 12 months, 24 patients (19.5\%) had missing data and were excluded from the study. Thus, a total of ninety-nine patients were ultimately enrolled in the study (Fig. 1).

Mean patient age was 80.1 years \pm 5.88 (range, $65-93$ years). $47,5 \%$ of the patients were aged 85 years or older. $62 \%$ were male. All patients were community-dwelling.

Colorectal cancer was the most prevalent cancer diagnosis ( $88 \%$ of the cases) while gastric cancer represented $12 \%$ of the cases. Patients had surgery for colon carcinoma in $64 \%$ of the cases and for rectal carcinoma in $36.5 \%$ of the colorectal cancer cases.

Patients with a diagnosis of colorectal cancer were classified as stage I (10\%), stage II (49\%), stage III (31\%) and stage IV (9\%) according to TNM V classification (Fig. 2). 


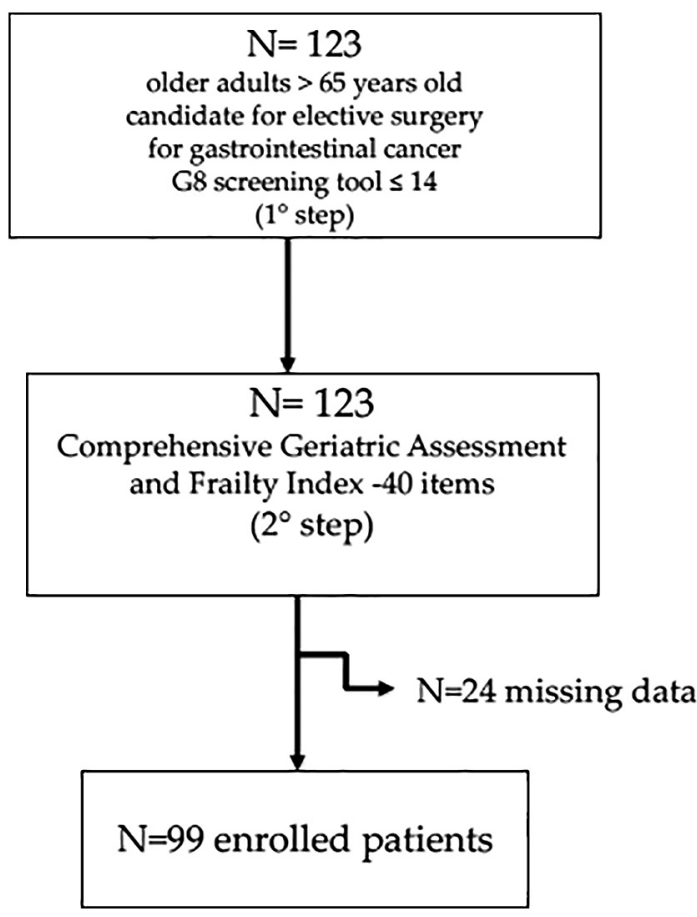

Fig. 1. Study design: patient's selection and two step oncogeriatric assessment.

Patients' clinical phenotype was characterized by multimorbidity, initial functional decline and malnutrition risk (Table 1 ).

Overall, 63 out of 99 patients $(63,6 \%)$ had deficits in more than three CGA clinical domains, which was indicative of a frail phenotype (Fig. 3).

According to the FI, 9 patients were fit (9\%), 50 were pre-frail (50,5\%) and 40 patients were frail (40,5\%) (Fig. 3 ).

Based on our CGA assessment, seventy patients received clinical therapeutic recommendations, with an average of 1.6 interventions per patient (range: $0-6$ ). The most frequent recommendations were nutritional interventions (56\%) and therapeutic interventions for pain (36\%) and mood (39\%) (Fig. 4).

The mean length of in-hospital stay was $8.8 \pm 1.2$ days.

\subsection{Short-Term Outcomes: 30 Days Mortality and Post-Operative Compli-} cations (Clavien-Dindo Classification)

\subsubsection{Short-Term Post-Operative Complications}

FI was the clinical variable that we found to be most closely associated with post-operative complications ( OR $=1.52$ (95\% CI:1.05$2.22) ; \mathrm{p}=0.027$ ), with an increase in post-operative complications by $52 \%$ corresponding to any FI increase by 0.1 points.

An impaired physical performance (as detected by time-up-and-go -TUG-test) was the clinical variable that showed the strongest
Table 1

Patients' clinical characteristics $(\mathrm{N}=99)$.

\begin{tabular}{|c|c|c|}
\hline Clinical variables & \multicolumn{2}{|l|}{$\%$} \\
\hline \multicolumn{3}{|l|}{ Demographics } \\
\hline \multicolumn{3}{|l|}{ Gender: } \\
\hline Female & \multicolumn{2}{|l|}{38} \\
\hline Male & \multicolumn{2}{|l|}{62} \\
\hline Mean age (sd) & \multicolumn{2}{|c|}{$80.18 \pm 5.88$ (range $65-93$ years) } \\
\hline \multicolumn{3}{|l|}{ Age groups } \\
\hline$<70$ & \multicolumn{2}{|l|}{5} \\
\hline $71-75$ & \multicolumn{2}{|l|}{17} \\
\hline $76-80$ & \multicolumn{2}{|l|}{31} \\
\hline $81-85$ & \multicolumn{2}{|l|}{29} \\
\hline $86-90$ & \multicolumn{2}{|c|}{13} \\
\hline$>91$ & \multicolumn{2}{|l|}{5} \\
\hline Screening tool, Cga assessment, Frailty assessmnt & Cut off & mean score $( \pm \mathrm{sd})$ \\
\hline G8 screening tool & $\leq 14$ & $12.4 \pm 2.3$ \\
\hline Mmse & $<24$ & $27.10 \pm 3.49$ \\
\hline Cdt (schulman) & $\geq 3$ & $2.53 \pm 1.44$ \\
\hline Mna & $<23$ & $23.12 \pm 3.31$ \\
\hline Iadl & $\leq 7$ & $7.08 \pm 1.73$ \\
\hline Barthel index & $<50$ & $97.48 \pm 6.54$ \\
\hline Cirs severity & & $2.01 \pm 0.34$ \\
\hline Cirs comorbidity & $>3$ & $4.46 \pm 1.79$ \\
\hline $\mathrm{N}^{\circ}$ of drugs & $\geq 3$ & $4.74 \pm 2.83$ \\
\hline Gds & $\geq 5$ & $3.92 \pm 3.34$ \\
\hline Tinetti scale & $\leq 18$ & $24.33 \pm 5.35$ \\
\hline Morse scale & $\geq 25$ & $21.10 \pm 15.77$ \\
\hline Gijon scale & $\geq 10$ & $8.80 \pm 2.44$ \\
\hline Cut off cga & $\geq 3$ & $3.49 \pm 2.28$ \\
\hline $\mathrm{Fi}$ & & $0,22 \pm 0,13$ \\
\hline
\end{tabular}

association with post-operative complications ( $\mathrm{OR}=1.15$ (95\% $\mathrm{CI}: 1.00-1.33) ; \mathrm{p}=0.048$ ).

\subsubsection{Short-Term (30 Days) Mortality}

Short -term mortality rate was of $0.8 \%$ (8/96 patients).FI (AUC = 0.72:95\% CI: $0.53-0.90$ ) and CGA (AUC $=0.70 ; 95 \% \mathrm{CI}: 0.51-0.89$ ) showed similar predicative accuracy for short-term mortality $(\mathrm{p}=$ 0.73).

IADL was the clinical scored exhibiting the strongest association with short-term mortality ( $\mathrm{OR}=1.67 ; 95 \% \mathrm{CI}: 1.20-2.27$; $\mathrm{p}=0.002$ ). Specifically, an increase in mortality risk was demonstrated for any decline by 1-point of IADL.

\subsection{Long- Term Outcomes: One-Year Mortality}

One year after surgery for a gastrointestinal cancer, the mortality rate was $19 \%$ (19/99). In this group, $40 \%$ of the patients had stage IV cancer and 56\% had reported major post-operative complications (Fig. 5.). A pair-wise analysis of the ROC curves of CGA ( $n=99$; AUC $=0.72 ; 95 \%$ CI: 0.58-0.86) and FI ( $\mathrm{n}=99 ; \mathrm{AUC}=0.70 ; 95 \% \mathrm{CI}: 0.54-0.89)$ showed a similar accuracy for the two scores in identifying one-year mortality after cancer surgery ( $p=0.61$ ) (Fig. 6). The FI cut-off value of 0.19
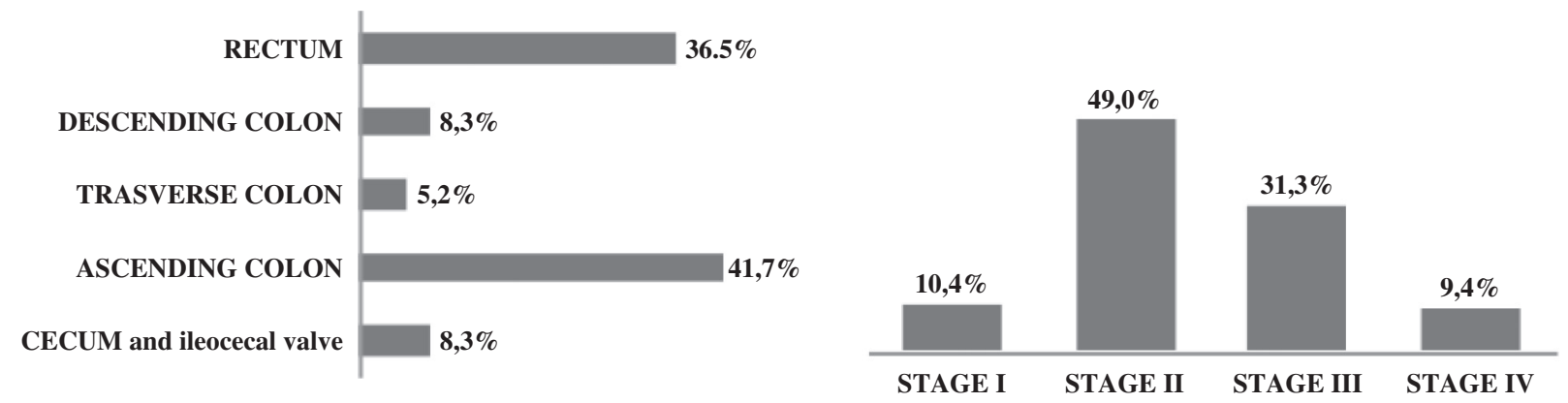

Fig. 2. Colorectal cancer distribution and stage. 

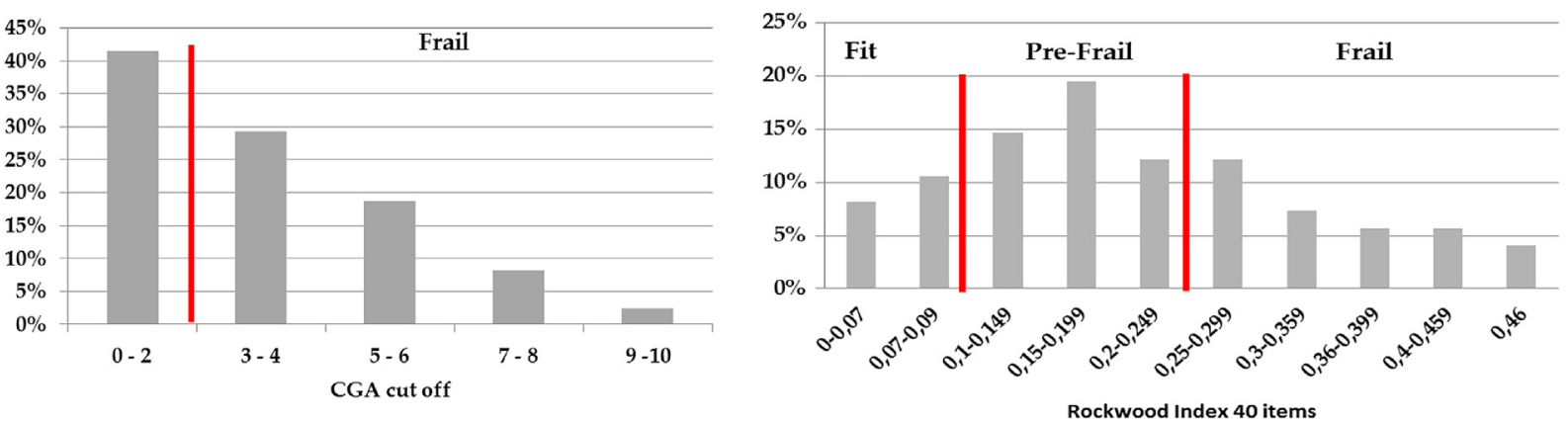

Fig. 3. Distribution of patients' clinical phenotype according to Comprehensive Geriatric Assessment and 40-Item Frailty Index IF.

(sensitivity:87.5\%; specificity: $51.1 \%$ ) showed the best predictive threshold for one-year mortality, whilst in the case of CGA, the best threshold predictive of one-year mortality was the value of 3 (sensitivity: $87.5 \%$; specificity: $44.3 \%$ ).

Our multivariate logistic regression analysis adjusted for age showed that functional decline in IADL (OR = 1.45; 95\% CI: $1.03-2$; $\mathrm{p}=0.033)$ and cancer stage $(\mathrm{OR}=3.28 ; 95 \% \mathrm{CI}$ : 0.91-11.8; $\mathrm{p}=$ 0.069 ) were the clinical variables with the strongest association with one-year mortality. In particular, for each sub-item decrease in the IADL score, the mortality risk was found to increase by $45 \%$. For each increase in cancer stage, the mortality risk was found to increase by $>3$ times. For the univariate analysis before stepwise logistic regression analysis see the Appendix B.

3.4. Long-Term Outcomes: Functional Status After One Year From Gastrointestinal Surgery

As compared to pre-morbid functional status, at one year after surgery for gastrointestinal cancer, a functional decline in basic activities of daily living was observed in $23 \%$ of patients, with an average loss of $5.6 \pm 15.8$ points on the Barthel Index, between the two-points assessment.

The pair-wise comparison of the ROC curves of CGA ( $\mathrm{n}=99$; $\mathrm{AUC}=$ 0.65 ; 95\% CI: $0.50-0.80)$ and $\mathrm{FI}(\mathrm{n}=99$; AUC $=0.69$; $95 \% \mathrm{CI}: 0.54-$ 0.85 ), showed similar accuracy in predicting patients' functional status at one year after surgery ( $\mathrm{p}=.45)$ (Fig. 7).

A FI cut off score between 0.15 (sensitivity: $76.5 \%$; specificity: $43.6 \%$ ) and 0.18 (sensitivity: $70.6 \%$; specificity: $52.7 \%$ ) showed the best predictive threshold for one-year functional decline. Similarly, a CGA cut off score of 3 (sensitivity: $64.7 \%$; specificity: $50.9 \%$ ) showed the best predictive threshold for one-year functional decline.

\section{Discussion}

The present study shows that, as compared to the gold standard CGA, the FI is very accurate in predicting the one-year mortality and functional status in a real-world population of elderly patients undergoing surgery for a gastrointestinal cancer. Furthermore, we also show that IADL and cancer stage are the key predictors of one-year mortality, with a decreased in mortality risk by $32 \%$ for each increase of sub items in the IADL score, adjusted for age and gender.

Functional status (IADL), physical performance (TUG) and FI also accurately predicted short-term outcomes, such as 30 days mortality and post-operative complications [45-50].

To date, few studies have investigated long-term outcomes, especially in very old oncological patients. Some of these studies have identified comorbidity, ASA classification, TNM stage and post-operative complications as key predictors of one-year mortality [19,26,51].

Previously, older patients with gastrointestinal cancer were reported to experience immediate post-operative functional decline, while about $11 \%$ of these old-age patients had permanent functional decline after 6 months from surgery [52].

The vast majority of elderly patients who are residents in nursing home were reported to have significant functional decline as a result of colon cancer surgery, although the lack of pre-operative frailty assessment prevented the generalization of the clinical findings [53].

A functional decline in IADL after colorectal cancer surgery was observed in a two-years observational follow up of octogenarian patients [26]. However, in this study, the perioperative CGA did not show any predictive role on long-term mortality and functional outcomes, due to the small sample size. In keeping with previous findings [18], comorbidity, functional decline in IADL, depression, and impaired nutrition, were the variables with the strongest ability to predict post-operative complications and early mortality.

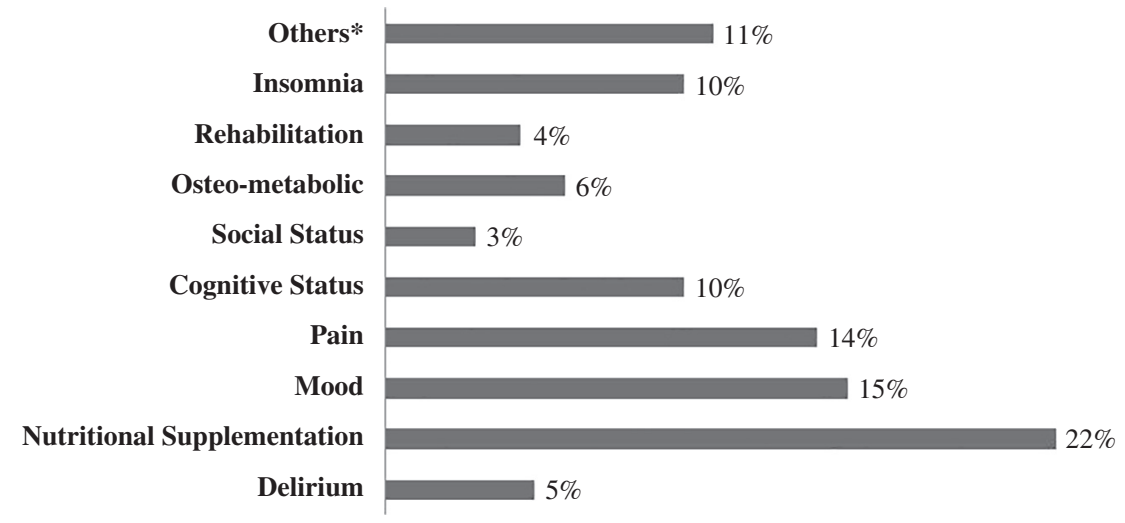

Fig. 4. Preoperative therapeutic recommendations based on CGA impaired clinical domains. 

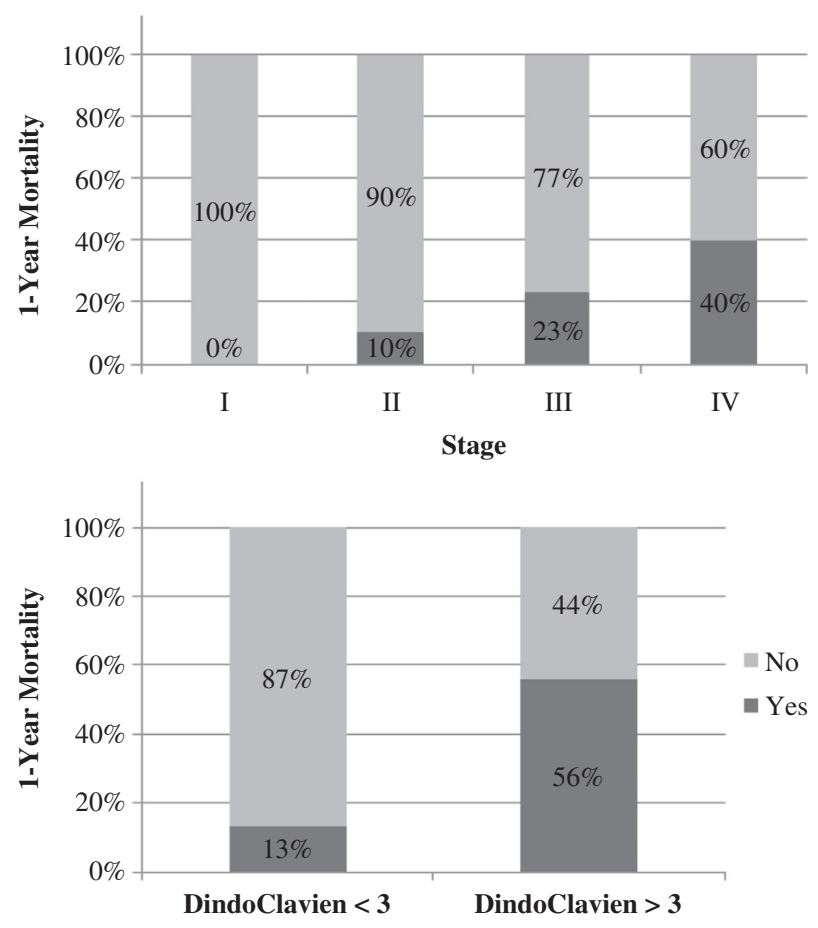

Fig. 5. One-year mortality patients' status on the basis of cancer stage (TNM 1-4 staging system) and post-operative complications (Clavien-Dindo Classification; $<2$ minor complications; > 3 major complications), respectively.

In the study by Ommundsen et al. [19], which also enrolled elderly patients with colorectal cancer, IADL, nutritional status and comorbidity were the most predictive variables for both short-term (1-year) and long-term (5-year) survival after surgery.

Hamaker et al. [54] observed a worsening functional trajectory after three months from colorectal cancer surgery (with a mean functional decline of $18 \%$ - range: $2 \%-39 \%$ ) and up to the first-year of follow-up, with permanent functional decline in older and frail patients.

The results of these studies indicate how patient-centered outcomes still receive poor attention as compared to traditional complications of surgery and to survival, whereas patient functional status and physical capacity should also be outcomes of primary interest, particularly in the older patient population [55].

Consistent with this notion, incorporating a perioperative frailty assessment of older cancer patients as a way to effectively predict immediate (30-day) post-operative complications and long-term mortality outcomes is now considered a priority [56].

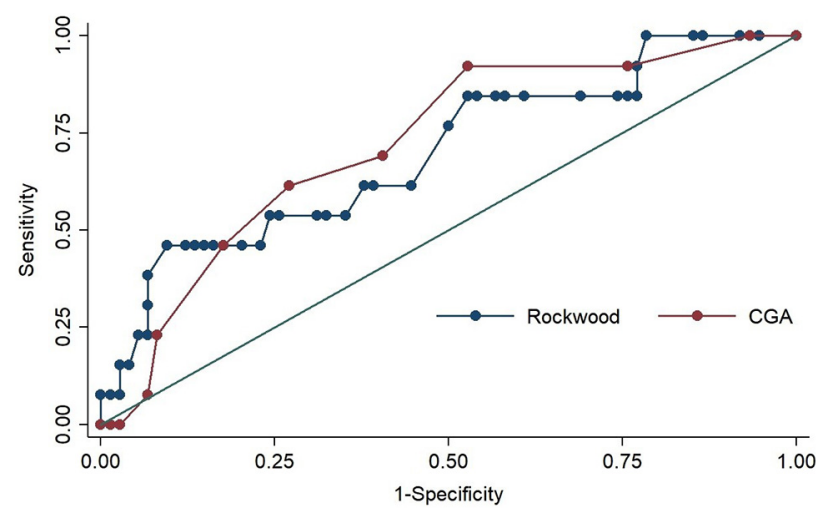

Fig. 6. ROC curve diagnostic accuracy comparison between CGA and 40-Item Frailty Index IF to predict one-year mortality.

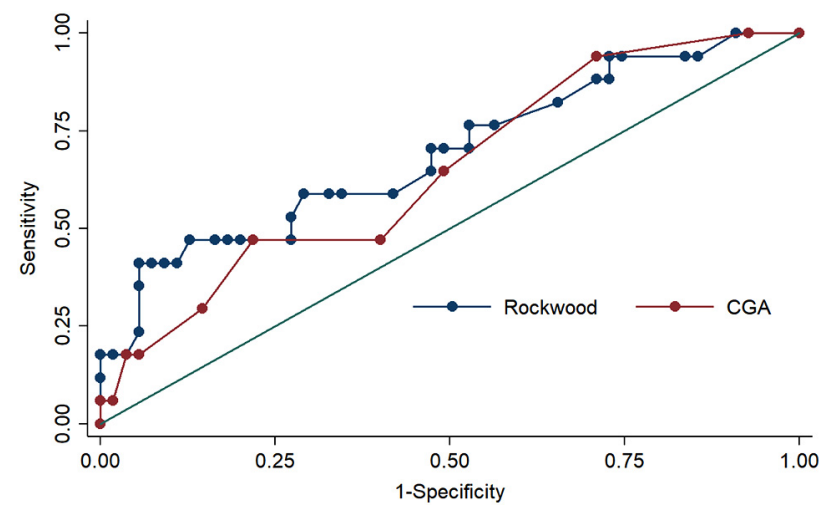

Fig. 7. ROC curve diagnostic accuracy comparison between CGA and 40-Item Frailty Index IF to predict functional status after one year from surgery.

In addition, obtaining more information on trajectories of frailty, functional decline, physical performance and cognitive status after major surgery for solid tumors has also become highly necessary, primarily for a more rationally planning of patient care and for conceiving and designing interventional studies. With this in mind, our study clearly indicates that the early preoperative assessment of functional status might unmask initial frailty trajectories that may reflect into short-term and long-term clinical outcomes as well.

Although the study was aimed at assessing the non-inferiority of FI as compared to CGA, it is noteworthy that measuring frailty allowed us to identify frailty cut-offs for the prediction of long-term outcomes. Namely, the FI cut off of 0.19 turned out to be the threshold for predicting mortality, while the cut off of 0.15 turned out to be the threshold for irreversible one-year functional decline. Indeed, also in our study, the frailty model based on the notion of accumulating clinical deficit seemed to better distinguish fit patients from vulnerable patients, thus delineating individualized clinical trajectories.

In addition, the identification of a frailty threshold, pointed out, at the same time, how frailty is a dynamic and potentially reversible syndrome at least at the initial stages.

These findings could lay the foundation for the implementation of systematic geriatric interventions in cancer older patients, as a way to reverse the homeostatic loss, recovering vulnerable patients to full oncological treatments.

The main limitations of our study are the single point preoperative frailty assessment and the single-centre population, that may represent a potential selection bias. In addition, intraoperative parameters, cancer disease progression/relapse, chemotherapy (changes or discontinuance) and re-hospitalizations were not systematically recorded during the observational period. However, they are part of ongoing research to assess patients' functional trajectories over time ( 2 years and more).

The strengths of our study are its prospective nature with long- term outcomes measurement, including functional status, in old age patients with gastrointestinal cancer. The systematic assessment of frailty, by virtue of the FI assessment, moved a step forward the understanding of long-term clinical outcomes after cancer surgery in the old age patients.

Although preliminary in nature, our definition of predictors of homeostatic loss is meant to help identify older subject with cancer, who are at the highest risk of seeing their vulnerability/frailty exacerbated by surgery. Based on our data, we propose that a severely impaired functional status may reflect the inability to react to treatment and/or act synergistically with cancer (especially if advanced in stage), leading to a failure-to-thrive status.

Studies that prioritize long-term outcomes related to functional status, rather than survival, are important for providing patients with reliable information on what to expect after cancer surgery. In line with this notion, the perioperative assessment of functional status and its clinical 
trajectory over time should be a key focus of disease-management teams dealing with elderly cancer patients.

Moreover, a better knowledge of old patients' functional trajectories will help tailoring surgical, medical and geriatric interventions in fit vs. vulnerable patients, potentially allowing a return to the premorbid functional status.

Systematic preoperative assessment of frailty in elderly cancer patients may help estimating surgical risk and identifies patients who might benefit from perioperative interventions designed to enhance physiologic reserve and to improve long-term clinical trajectories.

Eventually, frailty assessment in the surgical setting may become the ultimate framework for the decision-making process of disease management teams, guiding choices of surgical, medical and radiotherapy approaches based on a truly comprehensive vision of the elderly patient by virtue of their high biological heterogeneity.

\section{Author Contributions}

Chiara Giannotti (CG), Silvia Sambuceti (SS1), Alessio Signori (AS), Stefano Scabini (SS2), Emanuele Romairone (ER), Irene Caffa (IC), Alessio Nencioni (AN), Alberto Ballestrero (AB), Patrizio Odetti (PO), Fiammetta Monacelli (FM).

Study concepts: FM, CG, SS1, AN

Study design: FM, CG, SS

Data acquisition: CG, SS2, ER, SS1, IC
Quality control of data and algorithms: FM, AS

Data analysis and interpretation: FM, CG, AN; IC

Statistical analysis: AS, FM, CG

Manuscript preparation: FM, CG

Manuscript editing: FM, CG, PO, AB

Manuscript review: FM, PO, AN, AB

\section{Disclosures and Conflict of Interest Statements}

The authors have no conflicts of interest to disclose.

\section{Fundings}

None to declare.

\section{Acknowledgments}

This work was supported in part by AIRC IG \#17736 and \#22098 (to AN). By the Fondazione Umberto Veronesi, by the Italian Ministry of Health projects PE-2016-02363073 and by the $5 \times 1000$ Funds 2014 from the IRCCS Ospedale Policlinico San Martino (to A.N.). The authors would like to thank the residents in Geriatrics of Department of Internal Medicine and Medical Specialties (Genoa, Italy) for their help in data collection and analysis.

\section{Appendix A. Comprehensive Geriatric Assessment (CGA), Clinical Domain and Cut-Offs}

\begin{tabular}{|c|c|c|c|c|}
\hline Tool & Clinical domain & Number of items & Range & Cut-offs $^{\text {a }}$ \\
\hline Iadl [28] & Functional status & 8 & $0-8$ & $\leq 7$ \\
\hline Barthel index [29] & Functional status & 10 & $0-100$ & $<50$ \\
\hline Morse scale [30] & Risk of fall & 6 & $0-125$ & $\geq 25$ \\
\hline Tinetti scale [31] & Postural stability & 16 & $0-28$ & $\leq 18$ \\
\hline Cirs [32] & Comorbidity & 19 & $0-37$ & $>3$ \\
\hline Severity & & & $0-5$ & \\
\hline Comorbidity & & & $0-13$ & \\
\hline Mmse [33] & Cognitive status & 7 & $0-30$ & $<24$ \\
\hline Cdt [34] & Cognitive status & 1 & $1-6$ & $\geq 3$ \\
\hline Gds [35] & Psychological status & 15 & $0-15$ & $\geq 5$ \\
\hline Mna [36] & Nutritional status & 18 & $0-30$ & $<23$ \\
\hline Nrs [37] & Pain & 1 & $0-10$ & $\geq 3$ \\
\hline Gijon scale [38] & Social status & 5 & $5-25$ & $\geq 10$ \\
\hline Cga [41] & - & - & - & $\geq 3$ \\
\hline
\end{tabular}

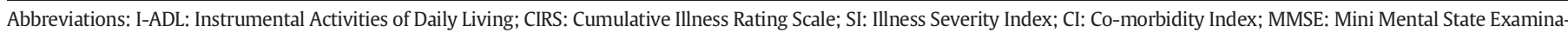
tion; CDT: Clock Drawing Test Shulman; GDS: Geriatric Depression Scale; MNA: Mini Nutritional Assessment; NRS: Numeric Rating Scale; CGA: Comprehensive Geriatric Assessment.

a Cut-off score.

Appendix B. Supplementary Table for Univariate and Multivariate Analysis

\begin{tabular}{|c|c|c|c|c|}
\hline \multirow{2}{*}{$\begin{array}{l}\text { Clinical domain } \\
\text { and tool mean } \\
\text { score }( \pm \text { sd })\end{array}$} & \multicolumn{2}{|c|}{ 1-Year mortality } & \multirow{2}{*}{$\begin{array}{l}\text { Univariate } \\
\text { Analysis } \\
\text { P value }^{\mathrm{a}}\end{array}$} & \multirow{2}{*}{$\begin{array}{l}\text { Multivariate } \\
\text { analysis OR } \\
\text { (95\% CI; P value) }\end{array}$} \\
\hline & $\begin{array}{l}\text { Patients } \\
\text { Who survived } \\
\text { N } 80\end{array}$ & $\begin{array}{l}\text { Patients } \\
\text { Who died } \\
\text { N } 19\end{array}$ & & \\
\hline Age & $80.2 \pm 5.604$ & $80.68 \pm 5.841$ & 0.032 & $\begin{array}{l}1.12(0.98-1.30) \\
\mathrm{p}=0.10\end{array}$ \\
\hline MMSE & $27.03 \pm 3.594$ & $27.47 \pm 2.951$ & 0.63 & \\
\hline CDT & $2.540 \pm 1.473$ & $2.438 \pm 1.209$ & 0.65 & \\
\hline Barthel Index & $98.46 \pm 4.519$ & $92.11 \pm 11.70$ & $\mathrm{P}<0.001$ & \\
\hline IADL & $7.279 \pm 1.517$ & $6.021 \pm 2.405$ & $\mathrm{P}<0.001$ & $\begin{array}{l}1.45(1.03-2) \\
\mathrm{p}=0.033\end{array}$ \\
\hline TUG & $10.16 \pm 4.371$ & $11.71 \pm 5.417$ & 0.22 & \\
\hline Tinetti Scale & $24.78 \pm 4.568$ & $21.72 \pm 8.266$ & 0.046 & \\
\hline Morse Scale & $19.86 \pm 13.30$ & $27.89 \pm 24.79$ & 0.037 & \\
\hline MNA & $23.46 \pm 3.120$ & $21.74 \pm 3.773$ & 0.12 & \\
\hline GDS & $4.45 \pm 3.70$ & $4.54 \pm 3.62$ & 0.24 & \\
\hline
\end{tabular}


(continued)

\begin{tabular}{|c|c|c|c|c|}
\hline \multirow{2}{*}{$\begin{array}{l}\text { Clinical domain } \\
\text { and tool mean } \\
\text { score }( \pm \text { sd })\end{array}$} & \multicolumn{2}{|c|}{ 1-Year mortality } & \multirow{2}{*}{$\begin{array}{l}\text { Univariate } \\
\text { Analysis } \\
\text { P value }^{\mathrm{a}}\end{array}$} & \multirow{2}{*}{$\begin{array}{l}\text { Multivariate } \\
\text { analysis OR } \\
\text { (95\% CI; P value) }\end{array}$} \\
\hline & $\begin{array}{l}\text { Patients } \\
\text { Who survived } \\
\text { N } 80\end{array}$ & $\begin{array}{l}\text { Patients } \\
\text { Who died } \\
\text { N } 19\end{array}$ & & \\
\hline Gijon Scale & $8.721 \pm 2.427$ & $9.263 \pm 2.535$ & 0.83 & \\
\hline CIRS comorbidity & $4.337 \pm 1.760$ & $5.105 \pm 1.853$ & 0.085 & \\
\hline CIRS severity & $1.996 \pm 0.326$ & $2.074 \pm 0.391$ & 0.30 & \\
\hline $\mathrm{N}^{\circ}$ of drugs & $4.606 \pm 2.844$ & $5.5 \pm 2.728$ & 0.047 & \\
\hline FI & $0.204 \pm 0.116$ & $0.296 \pm 0.169$ & 0.012 & \\
\hline CGA cut off & $3.279 \pm 2.262$ & $4.632 \pm 2.060$ & 0.0044 & \\
\hline Clavien-Dindo & $1.152 \pm 1.173$ & $1.722 \pm 1.904$ & 0.0017 & \\
\hline $\begin{array}{l}\text { Stage of disease, } \\
\mathrm{n}(\%)\end{array}$ & & & 0.076 & $\begin{array}{l}3.28(0.91-11.8) \\
p=0.069\end{array}$ \\
\hline 1 & 11/11 (100) & $0 / 11$ & & \\
\hline 2 & $37 / 41(90.2)$ & $4 / 41(9.8)$ & & \\
\hline 3 & $27 / 35(77.1)$ & $8 / 35(22.9)$ & & \\
\hline 4 & $3 / 5(60)$ & $2 / 5(40)$ & & \\
\hline
\end{tabular}

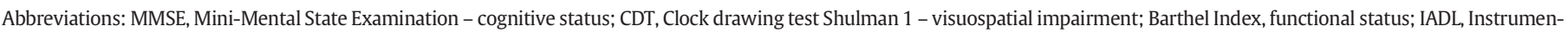

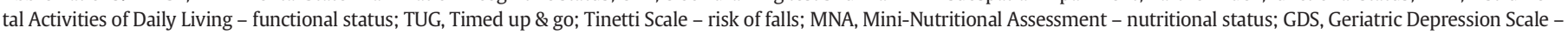

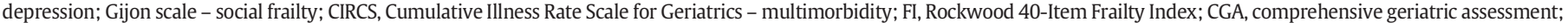
Clavien-Dindo - postoperative complications.

a Non-parametric Mann-Whitney $U$ test.

\section{References}

[1] Surveillance, epidemiology, and end results: SEER Cancer statistics review; 2010; 1975-2010, http://seer.cancer.gov/csr/1975_2010.

[2] Biondi G, Vacante M, Ambrosino I, Cristaldi E, Oietrapertosa G, Basile F, et al. Role of surgery for colorectal cancer in the elderly. World J Gastrointest Surg 2016;8: 606-13.

[3] Fearon KC, Jenkins JT, Carli F, Lassen K. Patient optimization for gastrointestinal cancer surgery. Br J Surg 2013;100:15-27.

[4] Mamidanna R, Almoudaris AM, Faiz O. Is 30-day mortality an appropriate measure of risk in elderly patients undergoing elective colorectal resection? Colorectal Dis 2012;14:1175-82.

[5] Dekker JW, van den Broek CB, Bastiaannet E, van de Geest LG, Tollenaar RA, Liefers GJ. Importance of the first postoperative year in the prognosis of elderly colorecta cancer patients. Ann Surg Oncol 2011;18:1533-9.

[6] Dekker JW, Gooiker GA, Bastiaannet E, van den Broek CB, van der Geest LG, van de Velde CJ, et al. Steering committee of the 'quality information system colorectal Cancer P. cause of death the first year after curative colorectal cancer surgery; a prolonged impact of the surgery in elderly colorectal cancer patients. Eur J Surg Oncol 2014;40:1481-7.

[7] Parks Ruth Mary, Rostoft Siri, Ommundsen Nina, Cheung Kwok-Leung. Peri-operative management of older adults with cancer-the roles of the surgeon and geriatrician. Cancers 2015;7:1605-21.

[8] Papamichael DR, Audisio A, Glimelius B, de Gramont A, Glynne-Jones R, Haller D, et al. Treatment of colorectal cancer in older patients: international Society of Geriatric Oncology (SIOG) consensus recommendations. Ann Oncol 2015;26:463-7.

[9] Tominaga Tetsuro, Nonaka Takashi, Takeshita Hiroaki, Kunizaki Masaki, Sumida Yorihisa, Hidaka Shigekazu, et al. The Charlson comorbidity index as an independent prognostic factor in older colorectal Cancer patients. Indian J Surg 2018;80:54-60.

[10] Van Gestel YR, Lemmens VE, de Hingh IH, Steevens J, Rutten HJ, Nieuwenhuijzen GA, et al. Influence of comorbidity and age on 1-, 2-, and 3-month postoperative mortality rates in gastrointestinal cancer patients. Ann Surg Oncol 2013;20:371-80.

[11] Makary Martin A, Segev Dorry L, Pronovost Peter J, Syin Dora, Bandeen-Roche Karen, Patel Purvi, et al. Frailty as a predictor of surgical outcomes in older patients. J Am Coll Surg 2010. https://doi.org/10.1016/j. jamcollsurg.2010.01.028.

[12] Wildiers H, Heeren P. PutsMet al. International society of geriatric oncology consensus on geriatric assessment in older patients with cancer. J Clin Oncol 2014;32: 2595-603.

[13] Chow WB, Rosenthal RA, Merkow RP, Ko CY, Esnaola NF, American College of Surgeons National Surgical Quality Improvement Program; American Geriatrics Society. Optimal preoperative assessment of the geriatric surgical patient: a best practices guideline from the American College of Surgeons National Surgical Quality Improvement Program and the American Geriatrics Society. J Am Coll Surg 2012 Oct;215(4): 453-66.

[14] Kenig Jakub, Olszewsk Urszul, Zychiewicz Beata, Barczynski Marcin, Mituś-Kenig Maria. Cumulative deficit model of geriatric assessment to predict the postoperative outcomes of older patients with solid abdominal cancer. J Geriatr Oncol 2015;31: 370-9.

[15] Kim Kwang-, Park Kay-Hyun, Koo Kyung-Hoi, Han Ho-Seong, Kim Cheol-Ho. Comprehensive geriatric assessment can predict postoperative morbidity and mortality in elderly patients undergoing elective surgery. Arch Gerontol Geriatr 2013;56: 507-12.

[16] Kristjansson SR, Farinella E, Gaskell S, Audisio RA. Surgical risk and post-operative complications in older unfit cancer patients. Cancer Treat Rev 2009;35:499-502.

[17] Audisio RA, Pope D, Ramesh HSJ, Gennari R, van Leeuwen BL, West C, et al. Shall we operate? Preoperative assessment in elderly cancer patients (PACE) can help a SIOG surgical task force prospective study. Crit Rev Oncol Hematol 2008;65:156-63.
[18] Kristjansson SR, Nesbakken A, Jordhoy MS, Skovlund E, Audisio RA, Ho Johannessen, et al. Comprehensive geriatric assessment can predict complications in elderly patients after elective surgery for colorectal cancer: a prospective observational cohort study. Crit Rev Oncol Hematol 2010;76:208.

[19] Ommundsen N, Wyller TB, Nesbakken A, Jordhoy MS, Bakka A, Skovlund E, et al. Frailty is an independent predictor of survival in older patients with colorectal cancer. Oncologist 2014;19:1268-75.

[20] Lin HS, Watts JN, Peel NM, Hubbard RE. Frailty and post-operative outcomes in older surgical patients: a systematic review. BMC Geriatr 2016 Aug 31;16(1): 157.

[21] Buigues Cristina, Juarros-Folgado Pilar, Fernández-Garrido Julio, Navarro-Martínez Rut, Cauli Omar. Frailty syndrome and pre-operative risk evaluation: a systematic review. Arch Gerontol Geriatr 2015;61:309-21.

[22] Lin H, Peel NM, Scott IA, Vardesh DL, Sivalingam P, McBride RL, et al. Perioperative assessment of older surgical patients using a frailty index-feasibility and association with adverse post-operative outcomes. Anaesth Intensive Care 2017 Nov;45(6): 676-82.

[23] Mosquera Catalina, Spaniolas Konstantinos, Fitzgerald Timothy L. Impact of frailty on surgical outcomes: the right patient for the right procedure. Surgery 2016;160: 272-80.

[24] Kok-Yang Tan MBBS, Med M, Surg FRCS, Yutaka J, Kawamura MDPHD, Aika Tokomitsu MD, et al. Assessment for frailty is useful for predicting morbidity in elderly patients undergoing colorectal cancer resection whose comorbidities are already optimized. Am J Surg 2012;204:139-43.

[25] Monique G, Huisman RA, Audisio G, Ugolini I, Montroni A, Vigano J, et al. Screening for predictors of adverse outcome in onco-geriatric surgical patients: a multicenter prospective cohort study. EJSO 2015;41:844-51.

[26] Rønning B, Wyller TB, Jordhøy MS, Nesbakken A, Bakka A, Seljeflot I, et al. Frailty indicators and functional status in older patients after colorectal cancer surgery. J Geriatr Oncol 2014 Jan;5(1):26-32. https://doi.org/10.1016/j.jgo.2013.08.001 [Epub 2013 Aug 30].

[27] Bellera CA, Rainfray M, Mathoulin-Pélissier S, Mertens C, Delva F, Fonck M, et al. Screening older cancer patients: first evaluation of the G-8 geriatric screening tool. Ann Oncol 2012;23:2166-72.

[28] Lawton MP, Brody EM. Assessment of older people: self-maintaining and instrumental activities of daily living. Gerontologist 1969;9:179-86.

[29] Mahoney FI, Barthel DW. Functional evaluation: the Barthel index. Md State Med J $1965 ; 14: 61-5$.

[30] Morse JM. Predicting fall risk. Can J Nurs Res 1998;30(11-2).

[31] Köpke S, Meyer G. The Tinetti test: Babylon in geriatric assessment. Z Gerontol Geriatr 2006;39:288-91.

[32] Linn BS, Linn MW, Gurel L. Cumulative illness rating scale. J Am Geriatr Soc 1968;16: 622-6.

[33] Folstein MF, Folstein SE, McHugh PR. "Mini-mental state". A practical method for grading the cognitive state of patients for the clinician. J Psychiatr Res 1975;12: 189-98.

[34] Shulman KI. Clock-drawing: is it the ideal cognitive screening test? Int J Geriatr Psychiatry 2000;15:548-61.

[35] Yesavage JA, Brink TL, Rose TL, Lum O, Huang V, Adey M, et al. Development and validation of a geriatric depression screening scale: a preliminary report. J Psychiatr Res 1982;17:37-49.

[36] Guigoz Y, Vellas B. The mini nutritional assessment (MNA) for grading the nutritional state of elderly patients: presentation of the MNA, history and validation. Nestle Nutr Workshop Ser Clin Perform Programme 1999;1:3-11.

[37] Paice JA, Cohen FL. Validity of a verbally administered numeric rating scale to measure cancer pain intensity. Cancer Nurs 1997;20:88-93. 
[38] García González JV, Díaz Palacios E, Salamea García A, Cabrera González D, Menéndez Caicoya A, Fernández Sánchez A, et al. An evaluation of the feasibility and validity of a scale of social assessment of the elderly. Aten Primaria 1999;23: $434-40$.

[39] Rockwood K, Song X, MacKnight C, Bergman H, Hogan DB, McDowell I, et al. A global clinical measure of fitness and frailty in elderly people. CMAJ 2005;173: $489-95$.

[40] Rockwood K, Mitnitski A. Frailty defined by deficit accumulation and geriatric medicine defined by frailty. Clin Geriatr Med 2011;27:17-26.

[41] Handforth C, Clegg A, Young C, Simpkins S, Seymour MT, Selby PJ, et al. The prevalence and outcomes of frailty in older cancer patients: a systematic review. Ann Oncol 2015;26:1091-101.

[42] Podsiadlo D, Richardson S. The timed "up \& go": a test of basic functional mobility for frail elderly persons. J Am Geriatr Soc 1991;39:142-8.

[43] Clavien PA, Barkun J, de Oliveira ML, et al. The Clavien-Dindo classification of surgical complications: five-year experience. Ann Surg 2009;250:187-96.

[44] Della Pietra GL, Savio K, Oddone E, Reggiani M, Monaco F, Leone MA. Validity and reliability of the Barthel index administered by telephone. Stroke 2011 Jul;42(7): 2077-9.

[45] Fagard K, Leonard S, Deschodt M, Devriendt E, Wolthuis A, Prenen H, et al. The impact of frailty on postoperative outcomes in individuals aged 65 and over undergoing elective surgery for colorectal cancer: a systematic review. J Geriatr Oncol 2016; 7:479-91.

[46] Tan KY, Kawamura YJ, Tokomitsu A, Tang T. Assessment for frailty is useful for predicting morbidity in elderly patients undergoing colorectal cancer resection whose comorbidities are already optimized. Am J Surg 2012 Aug;204 (2):139-43.

[47] Vermillion Sarah A, Hsu Fang-Chi, Dorrell Robert D, Shen Perry, Clark Clancy J. Modified frailty index predicts postoperative outcomes in older gastrointestinal cancer patients. J Surg Oncol 2017;115:997-1003.
[48] Pandit V, Khan M, Martinez C, Jehan F, Zeeshan M, Koblinski J, et al. A modified frailty index predicts adverse outcomes among patients with colon cancer undergoing surgical intervention. Am J Surg 2018 Jul 9;216:1090-4. https://doi.org/10.1016/j. amjsurg.2018.07.006 (Epub 2018 Jul 9).

[49] Velanovich V, Antoine H, Swartz A, Peters D, Rubinfeld I. Accumulating deficits model of frailty and postoperative mortality and morbidity: its application to a national database. J Surg Res 2013 Jul;183(1):104-10.

[50] Saxton A, Velanovich V. Preoperative frailty and quality of life as predictors of postoperative complications. Ann Surg 2011;253:1223-9.

[51] Kim Young Wan, Ik Yong Kim. Factors associated with postoperative complications and 1-year mortality after surgery for colorectal cancer in octogenarians and nonagenarians. Clin Interv Aging 2016(11):689-97.

[52] Amemiya T, Oda K, Ando M, Kawamura T, Kitagawa Y, Okawa Y, et al. Activities of daily living and quality of life of elderly patients after elective surgery for gastric and colorectal cancers. Ann Surg 2007;246:222-8.

[53] Finlayson Emily, Zhao Shoujun, Boscardin W John, Fries Brant E, Landefeld C Seth, Dudley R Adams. Functional status after colon cancer surgery in elderly nursing home residents. J Am Geriatr Soc 2012;60:967-73.

[54] Hamaker ME, Prins MC, Schiphorst AH, van Tuyl SA, Pronk A, van den Bos F. Longterm changes in physical capacity after colorectal cancer treatment. J Geriatr Oncol 2015;6:153-64.

[55] Kunitake H, Zingmond DS, Ryoo J, Ko CY. Caring for octogenarian and nonagenarian patients with colorectal cancer: what should our standards and expectations be? Dis Colon Rectum 2010 May;53(5):735-43.

[56] Rostoft S, Audisio RA. Recent advances in cancer surgery in older patients. F1000Res 2017 Jul 27;6:1242. 